\title{
Dependence of Properties
}

\author{
of Lithium Complex Greases Based \\ on Synthetic Base Oils from the Viscosity \\ of Dispersion Medium and the Composition \\ of the Thickener Agent
}

Irina S. Povkh a*, Boris P. Tonkonogova, Leonid N. Bagdasarova, Dmitry S. Kolybelsky ${ }^{\mathrm{b}}$ and Yaroslav V. Porfiryev ${ }^{\mathrm{b}}$

${ }^{a}$ Gubkin Russian State University of Oil and Gas 65 Leninskiy prospect, Moscow, 119991, Russia ${ }^{b}$ OJSC «Rosneft»-Moscow Plant «Nefteproduct» 40 Shosse Entuziastov, Moscow, 105118, Russia

This experiment is concerned with the preparation of a lithium complex soap grease having some principal advantages: good low temperature properties and high dropping point. As a thickener high molecular weight fatty acids (12-hydroxystearic acid) and aliphatic dicarboxylic acids (sebacic acid) were used. Dependence of properties of lithium complex greases based on synthetic base oils from the viscosity of dispersion medium were studied. The resulting samples satisfy the requirements of the lithium complex soap greases, also have better low temperature properties Present results may be used for the further development of the technology of lithium complex soap grease producing.

Keywords: grease, lithium complex soap grease, thickening agent, aliphatic dicarboxylic acid, dispersion medium, disperse phase.

(c) Siberian Federal University. All rights reserved

* Corresponding author E-mail address: povkhchem@list.ru 


\title{
Исследование зависимости
}

свойств комплексных литиевых смазок

на основе синтетических базовых масел

от вязкости дисперсионной среды

и состава дисперсной фазы

\author{
И.С. Повх ${ }^{\mathrm{a}}$, Б.П. Тонконогов ${ }^{\mathrm{a}}$, \\ Л.Н. Багдасаров ${ }^{a}$, Д.С. Колыбельский ${ }^{6}$, Я.В. Порфирьев ${ }^{\sigma}$ \\ ${ }^{a}$ Российский государственный университет нефти \\ и газа имени И.М. Губкина \\ Россия, 119991, Москва, Ленинский пр., 65 \\ ${ }^{6} \mathrm{OAO}$ «HК «Роснефть» - М3 «Нефтепродукт» \\ Россия, 105118, Москва, Шоссе Энтузиастов, 40
}

\begin{abstract}
Для улучшения эксплуатационных характеристик литиевых пластичных смазок и растирения температурного интервала их работоспособности исследованы опытные образиы смазок, имеющие хорошие низкотемпературные свойства и высокую температуру каплепадения, относящиеся $\kappa$ типу комплексных литиевых смазок. В качестве дисперсной фазы использовали совместно полученные (комплексные) соли 12-оксистеариновой и себациновой кислот. Изучена зависимость эксплуатационных свойств комплексных литиевых смазок от вязкости дисперсионной среды, в качестве которой применены синтетические базовые масла. Полученные образиы удовлетворяют требованиям, предъявляемым $к$ товарным комплексным литиевым смазкам зарубежного производства, а также превосходят последние по низкотемпературным свойствам.
\end{abstract}

Ключевые слова: пластичные смазки, комплексные литиевые смазки, загуститель, двухосновная карбоновая кислота, дисперсная фаза, дисперсионная среда.

\section{Введение}

Несмотря на относительно небольшой объем производства пластичных смазок (по данным NLGI, мировая выработка составляет около 1 млн т/год), они являются одним из важных и незаменимых видов смазочных материалов $[1,2]$. Это обусловлено ценными эксплуатационными свойствами пластичных смазок, весьма малым, иногда в сотни и тысячи раз меньшим по сравнению с маслами, удельным расходом, упрощением при их применении конструкций машин и механизмов, что снижает металлоемкость последних, повышает их надежность и ресурс работы. Кроме того, применение пластичных смазок увеличивает продолжительность межсервисных периодов и значительно сокращает расходы на обслуживание техники.

Расширение сферы применения пластичных смазок обусловлено непрерывным повышением их качества, которое определяется как организацией производства новых типов смазок с высокоэффективными дисперсными фазами, так и совершенствованием существующих техно- 
логий. К числу перспективных пластичных смазок относятся комплексные литиевые смазки, обладающие более высокими эксплуатационными показателями, чем смазки на однокомпонентных загустителях (Литол-24, Фиол-2 и др.) [3, 4].

Комплексные литиевые смазки предназначены для узлов трения, эксплуатируемых в условиях повышенных температур, силовых и скоростных нагрузок. Выбор для таких смазок дисперсионной среды, которая не только влияет на формирование их структуры, но и определяет работоспособность, - важная и трудоемкая задача. В России комплексные литиевые смазки выпускают в очень ограниченном количестве, в качестве основ используют в основном нефтяные (преимущественно остаточные) масла $[5,6]$.

Синтетические масла по сравнению с нефтяными обладают более высоким индексом вязкости, имеют лучшие низкотемпературные свойства, более высокую термоокислительную стабильность, обеспечивают весьма незначительную величину коэффициента трения и, самое главное, характеризуются, как правило, лучшими экологическими характеристиками [7].

Разработка составов комплексных литиевых смазок на основе синтетических базовых масел для получения продуктов с универсальными свойствами, доступных к применению в широком диапазоне как отрицательных, так и положительных температур, является целью данной работы.

\section{Материалы и методы}

В данной работе в качестве основной омыляемой жировой основы использовалась 12оксистеариновая кислота (12-HoSt), полученная путем гидрирования, омыления и разложения касторового масла. В ходе исследования возможности введения в состав дисперсной фазы двухосновных карбоновых кислот как комплексообразователей было установлено, что себациновая кислота оказывает наибольший загущающий эффект в используемых дисперсионных средах [8].

Характеристика омыляемых кислот приведена в табл. 1.

Для нейтрализации кислот и получения литиевых мыл использовали технический гидроксид лития.

Все модельные смазки приготовлены в среде базовых синтетических масел - масло № 1, масло № 2, масло № 3, масло № 4, масло № 5, - различающихся по вязкости (вяз-

Таблица 1. Характеристика кислот, входящих в состав дисперсной фазы

\begin{tabular}{|l|c|c|}
\hline \multicolumn{1}{|c|}{ Показатель } & 12-оксистеариновая кислота & Себациновая кислота \\
\hline Химическая формула & $\mathrm{C}_{18} \mathrm{H}_{36} \mathrm{O}_{3}$ & $\mathrm{C}_{10} \mathrm{H}_{18} \mathrm{O}_{4}$ \\
\hline $\begin{array}{l}\text { Молекулярная масса, } \\
\text { г/моль }\end{array}$ & 300,48 & 202,25 \\
\hline $\begin{array}{l}\text { Кислотное число, } \\
\text { мг КОН/г }\end{array}$ & 181,0 & 595,0 \\
\hline $\begin{array}{l}\text { Число омыления, } \\
\text { мг КОН/г }\end{array}$ & 177,0 & 554,0 \\
\hline Температура плавления, ${ }^{\circ} \mathrm{C}$ & 76 & 132 \\
\hline
\end{tabular}


Таблица 2. Основные показатели базовых масел

\begin{tabular}{|l|c|c|c|c|c|}
\hline $\begin{array}{c}\text { Наименование показателя/ } \\
\text { фактическое значение }\end{array}$ & Масло № 1 & Масло № 2 & Масло № 3 & Масло № 4 & Масло № 5 \\
\hline Индекс вязкости & 117 & 136 & 141 & 143 & 151 \\
\hline Плотность при $20^{\circ} \mathrm{C}$, кг $/ \mathrm{M}^{3}$ & 0,818 & 0,832 & 0,836 & 0,838 & 0,867 \\
\hline $\begin{array}{l}\text { Температура застывания, } \\
100{ }^{\circ} \mathrm{C}\end{array}$ & минус 72 & минус 50 & минус 48 & минус 46 & минус 40 \\
\hline $\begin{array}{l}\text { Температура вспышки в } \\
\text { открытом тигле, } 100{ }^{\circ} \mathrm{C}\end{array}$ & 222 & 270 & 274 & 278 & 286 \\
\hline Кислотное число, мг КОН/Г & отс. & отс. & отс. & отс. & отс. \\
\hline Содержание воды, \% & отс. & отс. & отс. & отс. & отс. \\
\hline
\end{tabular}

кость в ряду масел № 1-5 возрастает). Характеристика дисперсионной среды представлена в табл. 2.

В настоящей работе для оценки качества полученных смазок использованы следующие стандартные методы исследования:

- метод определения температуры каплепадения пластичных смазок (ГОСТ 6793);

- метод определения коллоидной стабильности пластичных смазок (ГОСТ 7142);

- метод определения предела прочности и термоупрочнения пластичных смазок (ГОСТ 7143);

- метод определения свободных щелочей и свободных органических кислот в пластичных смазках (ГОСТ 6707);

- метод определения эффективной вязкости нефтепродуктов автоматическим капиллярным вискозиметром (ГОСТ 7163);

- метод определения пенетрации пластичных смазок (ГОСТ 5436);

- метод определения испаряемости пластичных смазок (ГОСТ 9566);

- метод определения числа омыления (ГОСТ 5478);

- метод определения кинематической вязкости (ГОСТ 33);

- метод расчета индекса вязкости (ГОСТ 25371);

- метод определения плотности (ГОСТ 3900);

- методы определения температур текучести и застывания (ГОСТ 20287);

- методы определения температур вспышки и воспламенения в открытом тигле (ГОСТ 4333);

- метод определения кислотности и кислотного числа (ГОСТ 5985);

- метод определения содержания воды (ГОСТ 2477);

- метод определения интервала температуры плавления (ГОСТ 18995.4).

Технологию приготовления комплексных литиевых смазок можно разделить на пять последовательных стадий.

На первой стадии в дисперсионной среде происходит растворение 12-оксистеариновой и себациновой кислот с получением кислотно-масляной смеси. Процесс происходит при нагревании компонентов до температуры образования расплава кислоты-комплексообразователя.

$$
-56-
$$




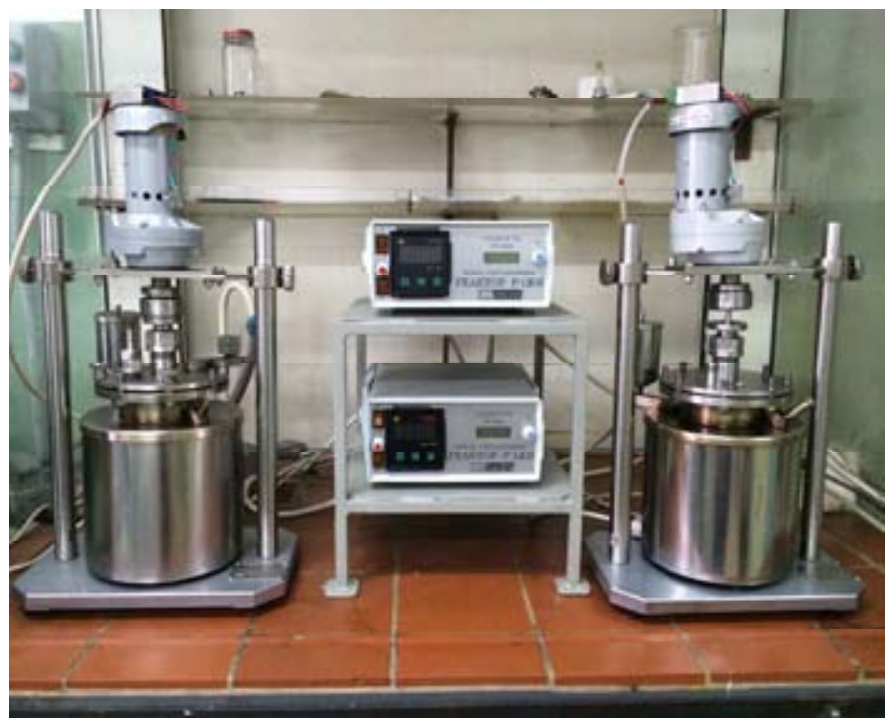

Рис. 1. Фотография реактора Р1-ЖВ

Следующая стадия характеризуется охлаждением кислотно-масляной смеси до температуры ниже точки кипения воды и нейтрализацией кислот избыточным количеством водного раствора гидроокиси лития (15-20 \%), рассчитанным по показателям чисел омыления используемых кислот. Далее необходимо поддержание условий реакции на заданном уровне не менее 30 мин для завершения процесса омыления.

На третьей стадии происходит постепенное увеличение температуры по мере выпарки воды из реакционной смеси.

Четвертая стадия характеризуется нагревом технологической среды до температуры $220^{\circ} \mathrm{C}$ и выдержкой при этой температуре в течение 15 мин. На данной стадии происходит распределение волокон полученного комплексного мыла в дисперсионной среде, протекает процесс структурирования дисперсной фазы.

Пятая стадия включает процессы охлаждения и гомогенизации смазки. Охлаждение образцов смазки производилось в объеме при перемешивании.

Все модельные смазки приготовлены в специально разработанном лабораторном реакторе Р-1ЖВ, выполненном из стали и закрывающемся герметично. Реактор состоит из рабочей емкости с внешним подогревом через рубашку, заполненную высокотемпературным теплоносителем для исключения локальных перегревов; механической скребковой мешалки с частотой вращения от 0 до 150 об/мин; автоматического регулятора температуры, позволяющего поддерживать температурный режим на заданном уровне в течение определенного времени.

\section{Результаты и обсуждение}

Результаты, полученные в ходе приготовления комплексных литиевых смазок на вышеописанных маслах (образцы № 1-5), представлены в табл. 3. Содержание комплексного литиевого мыла в смазке и массовое соотношение 12-оксистеариновой и себациновой кислот (2:1) на первом этапе исследования не меняли. 
Показатель температуры каплепадения, являющийся определяющим условием образования комплексного литиевого мыла, для всех полученных смазок выше $250{ }^{\circ} \mathrm{C}$. Образец, в котором в качестве дисперсионной среды было использовано масло № 1, имеет консистенцию класса 4 NLGI, высокий предел прочности на сдвиг и низкую коллоидную стабильность. Образец смазки, приготовленный в среде масла № 5, характеризуется неудовлетворительными низкотемпературными свойствами наряду с низким пределом прочности на сдвиг. Набором оптимальных физико-химических свойств обладают смазки, в качестве среды которых использовались масла № 3 и № 4.

Для исследования возможности снижения содержания дисперсной фазы и изменения ее состава с целью получения оптимальных свойств комплексных литиевых смазок исследована смазка на основе масла № 4. Результаты исследования представлены в табл. 4.

При массовом соотношении 12-оксистеариновой кислоты к себациновой, равном 1:1 (образец № 6), очевидно, что загущающего эффекта полученного мыла недостаточно для формирования устойчивой структуры смазки.

Образцы смазок, полученные на комплексных литиевых мылах 12-оксистеариновой и себациновой кислот, взятых в массовом соотношении 1,5-4,0:1,0, имеют температуру каплепадения выше $250{ }^{\circ} \mathrm{C}$ (образцы № 7-12). Возрастание содержания 12-HoSt в дисперсной фазе до точки максимума, равной 3,0 мольным частям, сопровождается улучшением прочностных характеристик коллоидной стабильности, далее наблюдается обратный эффект.

Для сравнительной оценки свойств опытных образцов в качестве эталонов выбраны товарные продукты на основе синтетических масел и комплексном литиевом загустителе - пластичная смазка зарубежного производства и комплексная литиевая пластичная смазка «Элесма» (ТУ 0253-028-47419918-2009) (табл. 5).

Опытные образцы комплексных литиевых смазок превосходят эталонные по низкотемпературным свойствам (показатель эффективной вязкости смазок при отрицательной температуре). По другим показателям, представленным в табл. 5, опытные образцы не уступают эталонным смазкам.

Таблица 3. Характеристики образцов комплексных литиевых смазок

\begin{tabular}{|c|c|c|c|c|c|c|}
\hline 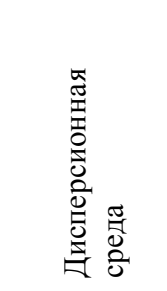 & 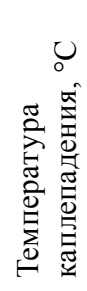 & 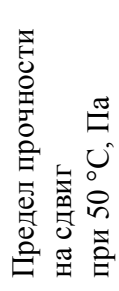 & 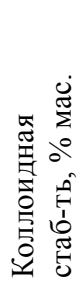 & 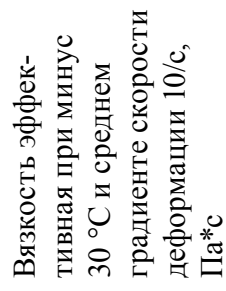 & 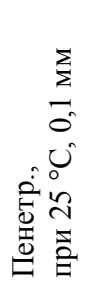 & 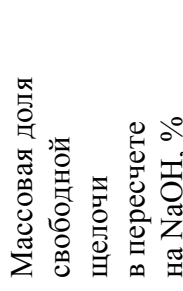 \\
\hline Масло № 1 & $>250$ & 980 & 15,1 & 617 & 195 & 0,02 \\
\hline Масло № 2 & $>250$ & 810 & 11,8 & 890 & 244 & 0,04 \\
\hline Масло № 3 & $>250$ & 630 & 7,4 & 980 & 249 & 0,02 \\
\hline Масло № 4 & $>250$ & 520 & 6,8 & 1047 & 250 & 0,03 \\
\hline Масло № 5 & $>250$ & 160 & 6,9 & 1905 & 290 & 0,03 \\
\hline
\end{tabular}


Таблица 4. Зависимость свойств смазки от состава дисперсной фазы

\begin{tabular}{|c|c|c|c|c|c|c|c|}
\hline $\begin{array}{c}\text { Показатель/массовое } \\
\text { соотношение } \mathrm{C}_{10} \mathrm{H}_{18} \mathrm{O}_{4}: \text { : } 2 \text {-HoSt* }\end{array}$ & $\begin{array}{c}\text { Образец } \\
\text { № } 6 \\
(1: 1,0)^{*}\end{array}$ & $\begin{array}{c}\text { Образец } \\
\text { № } 7 \\
(1: 1,5)\end{array}$ & $\begin{array}{c}\text { Образец } \\
\text { № } 8 \\
(1: 2,0)\end{array}$ & $\begin{array}{c}\text { Образец } \\
\text { № } 9 \\
(1: 2,5)\end{array}$ & $\begin{array}{c}\text { Образец } \\
\text { № } 10 \\
(1: 3,0)\end{array}$ & $\begin{array}{c}\text { Образец } \\
\text { № } 11 \\
(1: 3,5)\end{array}$ & $\begin{array}{c}\text { Образец } \\
\text { № } 12 \\
(1: 4,0)\end{array}$ \\
\hline Температура каплепадения, ${ }^{\circ} \mathrm{C}$ & 209 & $>250$ & $>250$ & $>250$ & $>250$ & $>250$ & $>250$ \\
\hline $\begin{array}{l}\text { Предел прочности } \\
\text { на сдвиг при } 50^{\circ} \mathrm{C}, \text { Па }\end{array}$ & 120 & 260 & 260 & 350 & 430 & 260 & 230 \\
\hline $\begin{array}{l}\text { Коллоидная стабильность, \% } \\
\text { выделенного масла }\end{array}$ & 13,0 & 12,6 & 8,8 & 8,4 & 8,1 & 11,48 & 11,70 \\
\hline $\begin{array}{l}\text { Вязкость эффективная } \\
\text { при минус } 30^{\circ} \mathrm{C} \text { и среднем } \\
\text { градиенте скорости } \\
\text { деформации } 10 / \mathrm{c}, \text { Па*c }\end{array}$ & 436 & 603 & 575 & 610 & 646 & 513 & 479 \\
\hline $\begin{array}{l}\text { Пенетрация при } 25^{\circ} \mathrm{C}, \\
\text { с перемешиванием } \\
60 \text { двойных тактов, } 0,1 \text { мм }\end{array}$ & 315 & 303 & 296 & 281 & 271 & 299 & 310 \\
\hline $\begin{array}{l}\text { Массовая доля свободной } \\
\text { щелочи в пересчете на } \mathrm{NaOH}, \%\end{array}$ & 0,03 & 0,02 & 0,04 & 0,03 & 0,03 & 0,02 & 0,03 \\
\hline
\end{tabular}

*Массовое соотношение $\mathrm{C}_{10} \mathrm{H}_{18} \mathrm{O}_{4}: 12-\mathrm{HoSt}$ - массовое соотношение себациновой кислоты к 12-оксистеариновой кислоте.

**Содержание дисперсной фазы во всех образцах одинаково (\% масс.).

Таблица 5. Сравнение свойств полученных образцов с эталонами

\begin{tabular}{|c|c|c|c|c|c|}
\hline Показатели & $1: 2,5$ & $1: 3,0$ & $\begin{array}{c}\text { Эталон } \\
\text { зарубежного } \\
\text { пр-ва }\end{array}$ & $\begin{array}{c}\text { Эталон } \\
\text { «Элесма» } \\
\text { (фактические } \\
\text { значения) } \\
\end{array}$ & $\begin{array}{c}\text { Эталон «Элесма» } \\
\text { (диапазон } \\
\text { допустимых } \\
\text { значений) }\end{array}$ \\
\hline Температура каплепадения, ${ }^{\circ} \mathrm{C}$ & $>250$ & $>250$ & $>250$ & 252 & Не ниже 250 \\
\hline $\begin{array}{l}\text { Предел прочности на сдвиг } \\
\text { при } 50^{\circ} \mathrm{C}, \text { Па }\end{array}$ & 350 & 430 & 320 & 420 & $350-550$ \\
\hline $\begin{array}{l}\text { Коллоидная стабильность, } \\
\text { \% масс }\end{array}$ & 8,4 & 8,1 & 8,9 & 6,0 & До 13 \\
\hline $\begin{array}{l}\text { Вязкость эффективная } \\
\text { при минус } 30^{\circ} \mathrm{C} \text { и среднем } \\
\text { градиенте скорости } \\
\text { деформации } 10 / \mathrm{c}, \text { Па*c }\end{array}$ & 610 & 646 & 1259 & 1100 & Не более 1100 \\
\hline Пенетрация при $25^{\circ} \mathrm{C}, 0,1$ мм & 281 & 271 & $265-295$ & 285 & $260-290$ \\
\hline $\begin{array}{l}\text { Испаряемость при } 120{ }^{\circ} \mathrm{C} \text { за } 1 \text { ч, } \\
\text { \%, не более }\end{array}$ & 0,72 & 0,66 & 1,79 & 0,5 & 1,0 \\
\hline
\end{tabular}

\section{Выводы}

Исследовано влияние вязкости дисперсионной среды на свойства комплексных литиевых смазок на основе класса синтетических базовых масел.

Установлено, что с возрастанием вязкости исходных базовых масел улучшается коллоидная стабильность, снижается предел прочности на сдвиг, ухудшаются низкотемпературные свойства смазок. 
Смазки, полученные на комплексных литиевых мылах 12-оксистеариновой и себациновой кислот, взятых в массовом соотношении 2,0-4,0:1, имеют температуру каплепадения выше $250{ }^{\circ} \mathrm{C}$.

Выявлено, что оптимальное соотношение основного омыляемого сырья (12-оксистеариновой кислоты) к кислоте-комплексообразователю (себациновой кислоте) варьируется в пределах 2,5-3,0:1 соответственно.

Физико-химические характеристики опытных образцов смазок на основе синтетических базовых масел (температура каплепадения, коллоидная стабильность, предел прочности на сдвиг, пенетрация и испаряемость) сопоставимы с характеристиками эталонных импортных смазок.

\section{Список литературы}

1. Lurz J.A. NLGI-Spokesman 2004. Vol. 67, № 10. P. 22-37.

2. Lurz J.A. NLGI-Spokesman January 2005. Vol. 68. № 10. P. 21-41.

3. Ищук Ю.Л. Состав, структура и свойства пластичных смазок. Киев: Наук. думка, 1996. 513 c. [Ishchuk Y.L. The composition, structure and properties of lubricating greases. Kiev: Naukova Dumka, 1996. 513 p. (In Russ.)]

4. Манг Т., Дрезель У. (ред.) Смазки. Производство, применение, свойства. Справочник: пер. 2-го англ. изд. под ред. В. М. Школьникова. - СПб.: ЦОП «Профессия», 2010. 944 с. [Тhео Mang and Wilfried Dresel. Lubricants and lubrication SpB: Professiya, 2010. 944 p. (In Russ.)]

5. Патент № 1446914 РФ. Ищук Ю.Л., Булгак В.Б., Дяченко Ю.П., Джой А.С., Красноперов О.И., Лендьел И.В., Василенко И.В., Еситашвили В.А., Недбайлюк П.Е., Шевченко В.Л., Прусак А.Г., Михалушкина Н.Г. Пластичная смазка. Опубл. 20.02.1996. [Patent 1446914 RU. Ishchuk Y.L., Bulhak V.B., Dyachenko Y.P., Joy A.S., Krasnopyorov O.I., Lengyel I.V., VasilenkoI.V., Esitashvili V.A., Nedbaylyuk P.E., Shevchenko V.L., Prusak A.G., Mihalushkina N.G. Lubricating grease. Publ. Date 20.02.1996. (In Russ.)]

6. Патент № 2217483 РФ. Елисеев Л.С., Нестеров А.В., Грачевский М.Б., Хромченков Б.С. Пластичная смазка. Опубл. 27.11.2003. [Patent 2217483 RU. Eliseev L.S., Nesterov A.V., Grachevsky M.B., Khromchenkov B.S. Lubricating grease. Publ. Date 27.11.2003. (In Russ.)]

7. Евдокимов А.Ю., Фукс И.Г., Любинин И.А. Смазочные материалы в техносфере и биосфере. Киев: Атика-Н, 2012. 292 с. [Evdokimov A.Yu., Fuchs I.G., Lyubinin I.A. Lubricants in a technosphere and the biosphere. Kiev: Atika-N, 2012. 292 p. (In Russ.)]

8. Повх И.С., Тонконогов Б.П., Багдасаров Л.Н., Порфирьев Я.В. Влияние состава загустителя на свойства комплексной литиевой смазки на основе синтетических базовых масел. Технологии нефти и газа. М.: Издательство РГУ нефти и газа им. И.М. Губкина. 2014. Т.6(95). C. 18-22 [Effect of the thickener composition on the properties of synthetic based lithium complex grease. Technologies of oil and Gas. Moscow: Gubkin State University of Oil and Gas. 2014. Vol.6 (95). p.18-22 (In Russ.)] 